\section{Heterogeneous vesicles in mucous epithelial cells of posterior esophagus of Chinese giant salamander (Andrias davidianus)}

\author{
H. Zhang, S. Zhong, T. Ge, S. Peng, P. Yu, \\ Z. Zhou, X. Guo \\ College of Animal Science and \\ Technology, Jiangxi Agricultural \\ University, Nanchang, China
}

\begin{abstract}
The Chinese giant salamander belongs to an old lineage of salamanders and endangered species. Many studies of breeding and disease regarding this amphibian had been implemented. However, the studies on the ultrastructure of this amphibian are rare. In this work, we provide a histological and ultrastructural investigation on posterior esophagus of Chinese giant salamander. The sections of amphibian esophagus were stained by hematoxylin and eosin. Moreover, the esophageal epithelium was observed by transmission electron microscopy. The results showed that esophageal epithelium was a single layer epithelium, which consisted of mucous cells and columnar cells. The esophageal glands were present in submucosa. The columnar cells were ciliated. According to the diverging ultrastructure of mucous vesicles, three types of mucous cells could be identified in the esophageal mucosa: i) electron-lucent vesicles mucous cell (ELVMC); ii) electron-dense vesicles mucous cell (EDV-MC); and iii) mixed vesicles mucous cell (MV-MC).
\end{abstract}

\section{Introduction}

Amphibians are important to understand early terrestrial evolution of tetrapods. They are poikilotherm and hardly have migratory ability with external environment change. Therefore, the amphibians are vulnerable to ecological environment, they are more threatened and are declining more rapidly than either birds or mammals. ${ }^{1}$ Furthermore, the amphibian skin contains various bioactive molecules that possess potent therapeutic activities like antibacterial, antifungal, antiprotozoal, antidiabetic, antineoplastic, analgesic and sleep inducing properties. ${ }^{2}$ In a word, amphibians have significant scientific research and ecological value.
The Chinese giant salamander, Andrias davidianus (Amphibia: Caudata), is an old lineage of amphibian and endangered species. It is the largest of all amphibian species in the world, reaching a maximum length of $170 \mathrm{~cm}$ and a weight of over $60 \mathrm{~kg}^{3}$ A. davidianus was once common and was regularly found in central and southern China before $1980 \mathrm{~s} .{ }^{4}$ However, with over-exploitation and habitat loss, the population of wild Chinese giant salamanders has declined dramatically and became an endangered species. ${ }^{3}$ The Chinese giant salamander is regarded as having an important value in scientific research and might be a key taxon to understand and reconstruct functional-evolutionary processes behind the early land of vertebrates. ${ }^{5,6}$ Hence, A. davidianus might also serve as a model system for studying cytobiological aspects of vertebrate evolution. The esophageal organization is highly variable and the feeding behavior, type of food and lifestyles might be related to esophageal specialized structure. ${ }^{7}$ Consistently with a previous study that reported on the esophageal microstructure of Chinese giant salamander, ${ }^{8}$ we hypothesized that the esophagus of this amphibian contains some specialized structure to meet their feeding habit and food types. However, our knowledge on the histology of the Chinese giant salamander is still very limited, in particular, the esophageal ultrastructure is absent. The purpose of this study is to analyze the micro- and ultrastructure of esophageal mucosa in Chinese giant salamander, and to contribute to our understanding of the feeding mechanism of this exceptional amphibian by esophageal specialized structure.

\section{Materials and Methods}

\section{Animals}

This work has been conducted under the Ethical Committee of Jiangxi Agricultural University after relevant ethical review according to the National Institutes of Health Guide for the Care and Use of Laboratory Animals. The four (2 males and 2 females) 2.5-year-old Chinese giant salamanders (weight: 0.99-1.12 kg) were raised with simulated ecological breeding technology in their primary habitat and were generously provided by an artificial breeding farm in mountain area, Jiangxi province, P. R. China. After the animals were euthanized on the ice, they were slaughtered.

\section{Histology}

For histological investigations, the posterior esophagus samples were fixed in $4 \%$
Correspondence: Xiaoquan Guo, College of Animal Science and Technology, Jiangxi Agricultural University, 1101 Zhimin Road, Nanchang 330045 , China.

Tel. +86.791.83813503 - Fax: +86.791 .83813504 . E-mail: xqguo20720@aliyun.com

Key words: Amphibian; esophagus; ultrastructure; mucous cells; heterogeneous vesicles.

Contributions: $\mathrm{HZ}$, concept and design, data acquisition and interpretation, article drafting, manuscript planning and writing; SZ, TG, experimental work, study execution and manuscript writing; SP, experimental assistance; ZZ, technical assistance; $\mathrm{XG}$, concept, writing and fund supply.

Funding: this work was supported by Science and Technology Program (Grant No. 20151BBF60007), Natural Science Foundation (Grant No. 20122BAB214021), Natural Science Foundation of Department of Education (Grant No. GJJ13262) and Special Postgraduate Innovation Foundation of Jiangxi Province, China (Grant No. YC2014 S194).

Conflict of interest: the authors declare no conflict of interest.

Received for publication: 13 April 2015. Accepted for publication: 16 July 2015 .

This work is licensed under a Creative Commons Attribution NonCommercial 3.0 License (CC BYNC 3.0).

\section{(C) Copyright H. Zhang et al., 2015}

Licensee PAGEPress, Italy

European Journal of Histochemistry 2015; 59:2521 doi:10.4081/ejh.2015.2521

paraformaldehyde for $24 \mathrm{~h}$ at room temperature, washed with $\mathrm{pH} 7.40 .1 \mathrm{M}$ phosphatebuffered saline (PBS), dehydrated in ethanol and embedded in paraffin. Five-micrometer sections were cut on a microtome (Yidi, Jinhua, China) and after removing the paraffin stained with hematoxylin and eosin (H\&E) for general morphology. After staining, the slides were mounted with permount under glass coverslips and analyzed with a BM 2000 light microscopy (Yongxin, Nanjing, China). The images were acquired by Scopelmage 9.0 (H3D) software (Yongxin).

\section{Transmission electron microscopy (TEM)}

For ultrastructural analyses, the small pieces of posterior esophageal epithelium were fixed in $2.5 \%$ glutaraldehyde/PBS for 24 $\mathrm{h}$ at $4^{\circ} \mathrm{C}$, and then washed three times in 0.1 M PBS (pH 7.4). The samples were post-fixed in $1 \% \mathrm{OsO}_{4}$ for $2 \mathrm{~h}$, washed three times in 0.1 M PBS, dehydrated in a graded ethanol series, 
and then dehydrated two times in acetone, embedded in Spurr's resin at $37^{\circ} \mathrm{C}$ for $24 \mathrm{~h}$, and polymerized at $60^{\circ} \mathrm{C}$ for $48 \mathrm{~h}$. The specimens were sectioned with LKB-V type of ultra microtome (Bromma, Stockholm, Sweden). Finally, the ultra-thin sections were observed and photographed by a Hitachi H-600 TEM (Tokyo, Japan).

\section{Measurement and statistics}

The height and width of mucous cells, columnar cells and cilia were measured by Image-Pro Plus 6.0 software (Media Cybernetics, Rockville, MD, USA). Data were analyzed by SPSS 17.0 software (IBM, Armonk, NY, USA).

\section{Results}

\section{Esophageal histology}

The schematic diagrams of the esophageal epithelium and cilia were drawn by their microstructural and ultrastructural features (Figure 1). The esophagus had several folds in its lumen. Light microscopy revealed that the esophageal wall consisted of four layers, namely mucosa, submucosa, muscularis externa and tunica externa (Figure 2A). The epithelial cells contained a number of single layer mucous cells and columnar cells, and displayed their columnar and pyramid-like shapes. The apical cytoplasm of the mucous cells was filled with eosin-weakly positive vesicles (Figure 2B). The blue-black nuclei adjoined basilar part of mucous cells. The large alveolar glands, esophageal glands were deeply embedded in submucosa (Figure 2A). The esophageal glands were tubuloacinar glands. The muscularis externa is well-developed in esophageal wall.

\section{Ultrastructure of esophageal epithelial cells}

TEM analyses showed that mucous cells and ciliated columnar cells were present in esophageal epithelium of Chinese giant salamanders (Figures 3, 4 and 5). Three types of mucous cells could be distinguished based on the appearance of their vesicles in transmission electron micrographs (Figures 3 and 5). The first type of mucous cells was filled with large electron-lucent secretory vesicles with homogeneous content and is called electronlucent vesicles mucous cell (ELV-MC). The second mucous cells type contained small moderately electron-dense secretory vesicles with two kinds of high electron-dense material, namely off-centered, fingerprint-like material and irregular thread material (Figures 6 and 7). This second mucous cell type is called electron-dense vesicles mucous cell (EDV-

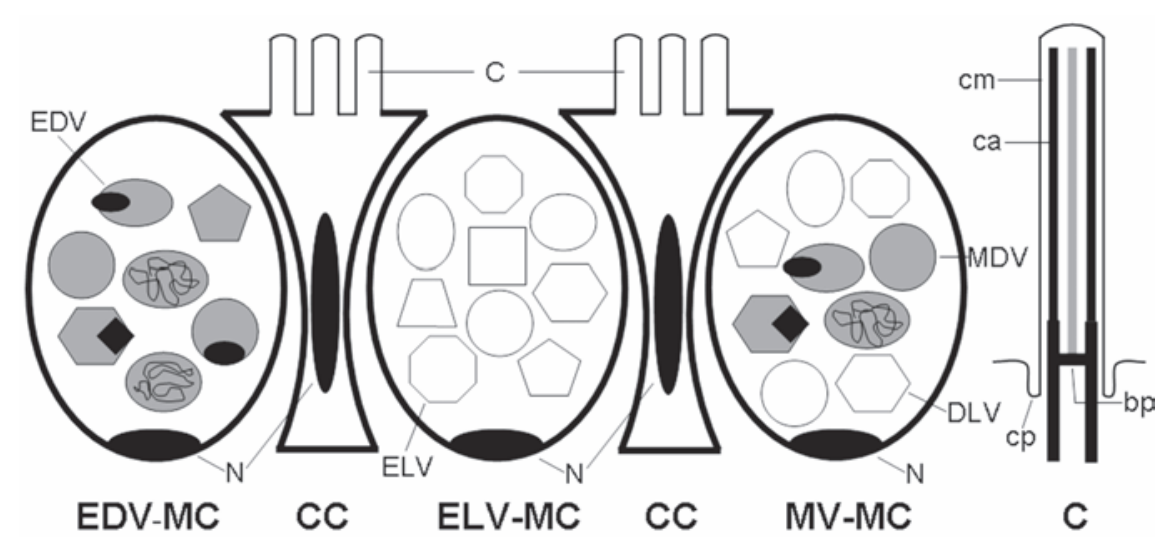

Figure 1. Schematic diagrams of the esophageal epithelium and cilia. ELV-MC, electronlucent vesicles mucous cell; EDV-MC, electron-dense vesicles mucous cell; MV-MC, mixed vesicles mucous cell; $\mathrm{CC}$, columnar cell; $\mathrm{C}$, cilia; $\mathrm{cm}$, ciliary membrane; ca, ciliary axoneme; cp, ciliary pocket; bp, basal plate; $N$, nucleus.
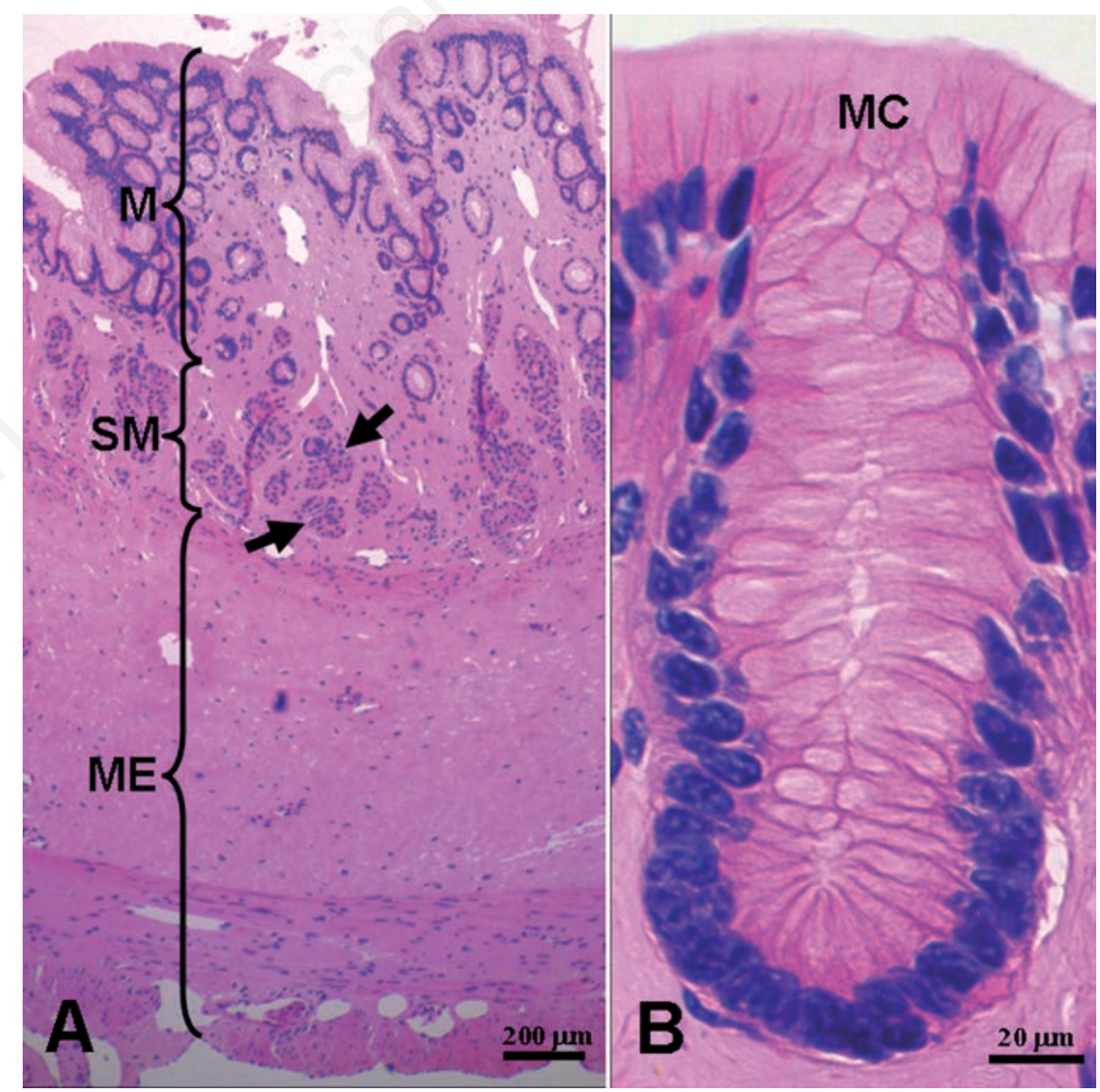

Figure 2. Histology of the esophagus. Panel B shows detail of epithelial cells. M, mucosa; SM, submucosa; ME, muscularis externa; MC, mucous cell. The arrows denote esophageal glands. 
$M C)$. The third type of mucous cells was filled with mixed-type secretory vesicles (Figures 3 and 5) and both moderately electron-dense vesicles and electron-lucent vesicles were present in the cytoplasm. Accordingly, the third mucous cell type is called mixed vesicles mucous cell (MV-MC). Organelles of all three mucous cells types were rare and their oblate nuclei of the mucous cells were compressed and lay on the proximal cell pole. In between the mucous cells, slender columnar cells with serried ranks of cilia could be observed (Figure 4).

\section{Results of statistics}

The results were shown in Table 1. All data were reported as mean \pm standard error of the mean.

\section{Discussion}

The general organization of posterior esophagus in Chinese giant salamanders containing four layers is similar to those of other amphibians, such as Rana perezi. $i^{9,10}$ Our results also present some differences from some amphibians. For example, the esophageal epithelium of Chinese giant salamanders is identical to Eurasian green toad, but esophageal wall of Eurasian green toad did not contain the esophageal glands. ${ }^{11}$ Moreover, the posterior esophageal epithelium of Chinese giant salamanders is a simple lining epithelium consisting of mucous cells and high columnar cells instead of stratified squamous epithelium in the esophagus of many others vertebrates. Unexpectedly, the epithelium turned out to be different from what was stated in Li's report showing that the epithelium of Chinese giant salamanders is a stratified columnar epithelium. ${ }^{8}$ We believe that the epithelium might be different in various esophageal segments of Chinese giant salamander. It needs further investigate in the future studies. The simple epithelium is also different from esophageal pseudostratified ciliated epithelium of Rana perezi. ${ }^{9}$ However, the esophageal epithelium of the amphibian is similar to that of some reptiles contained ciliated columnar cells and mucous secreting cells. ${ }^{12,13}$

In addition, three types of mucous cells vesicles were observed in esophageal epithelium by TEM in the present study. An additional cell type is MV-MC, which contained both moderately electron-dense vesicles and electron-lucent vesicles. This cell type has not been mentioned in previous works. In particular, the vesicles of EDV-MC contained high electron-dense, off-centered fingerprint-like material. This distinctive material has not
Table 1. The length and width of mucous cells, columnar cells and cilia.

\begin{tabular}{lccc} 
& Mucous cells $(\mu \mathrm{m})$ & Columnar cells $(\mu \mathrm{m})$ & Cilia $(\mu \mathrm{m})$ \\
Length & $41.00 \pm 9.96$ & $41.73 \pm 6.79$ & $7.67 \pm 0.54$ \\
Width & $19.94 \pm 7.49$ & $3.14 \pm 0.70$ & $0.19 \pm 0.27$ \\
\hline
\end{tabular}

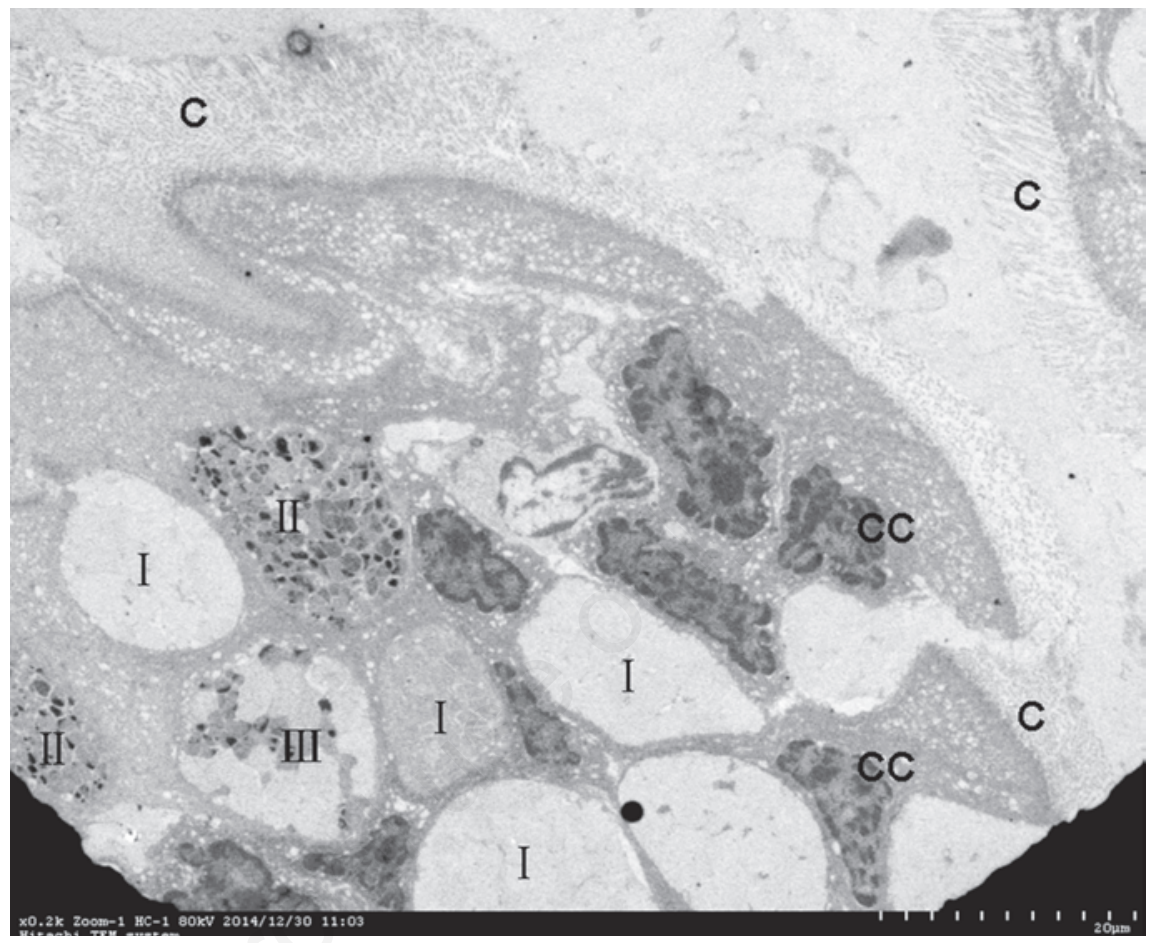

Figure 3. Three type mucous cells are present in esophageal epithelium. I, ELV-MC; II, EDV-MC; III, MV-MC; CC, columnar cell; $C$, cilia.

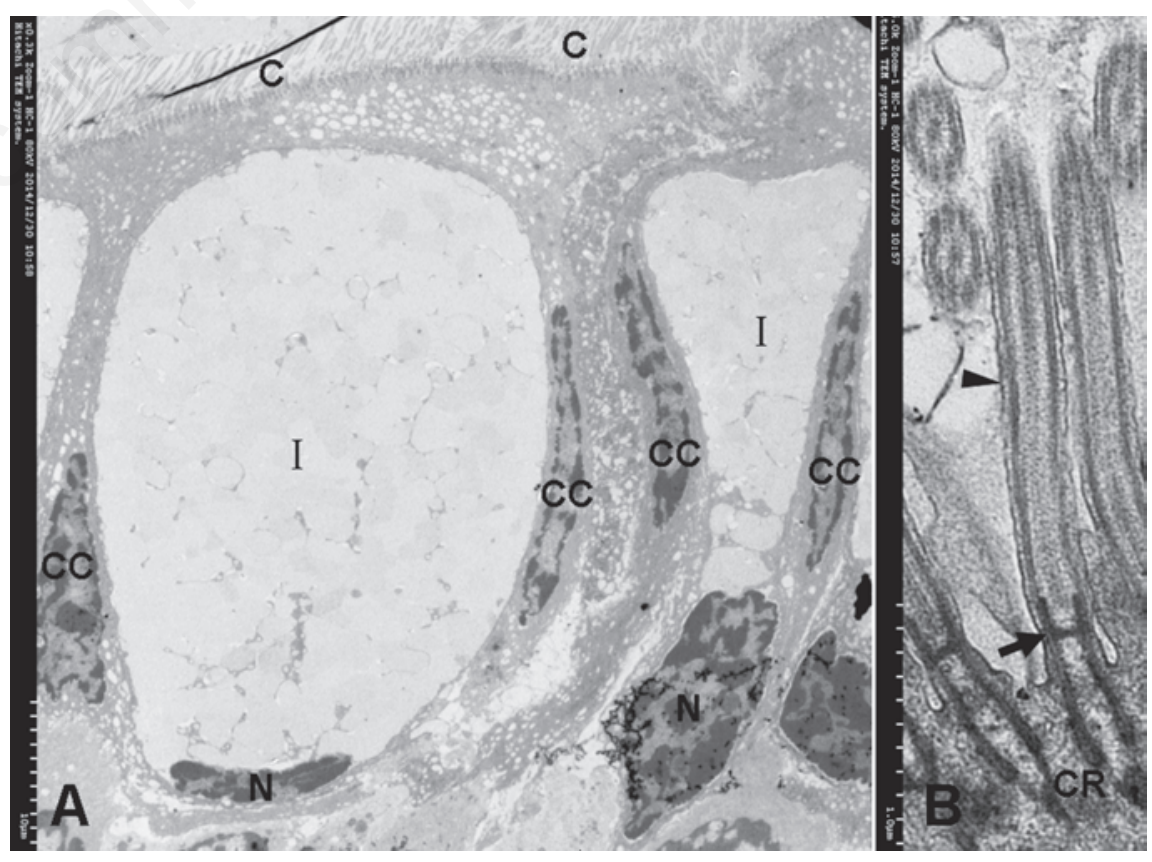

Figure 4. A) Structure of type I mucous cells (ELV-MC), columnar cell (CC). B) Detail of the cilia (C) are inserted in narrow sags of the cell apex by two electrondense cilialy rootlets (CR); two CR are connected by an electron-dense basal plate (arrow); two CR and a basal plate form a $\mathrm{H}$-type frame to facilitate fixation of axoneme; the ciliary axoneme extends from the basal plate. Arrowhead, ciliary membrane. 


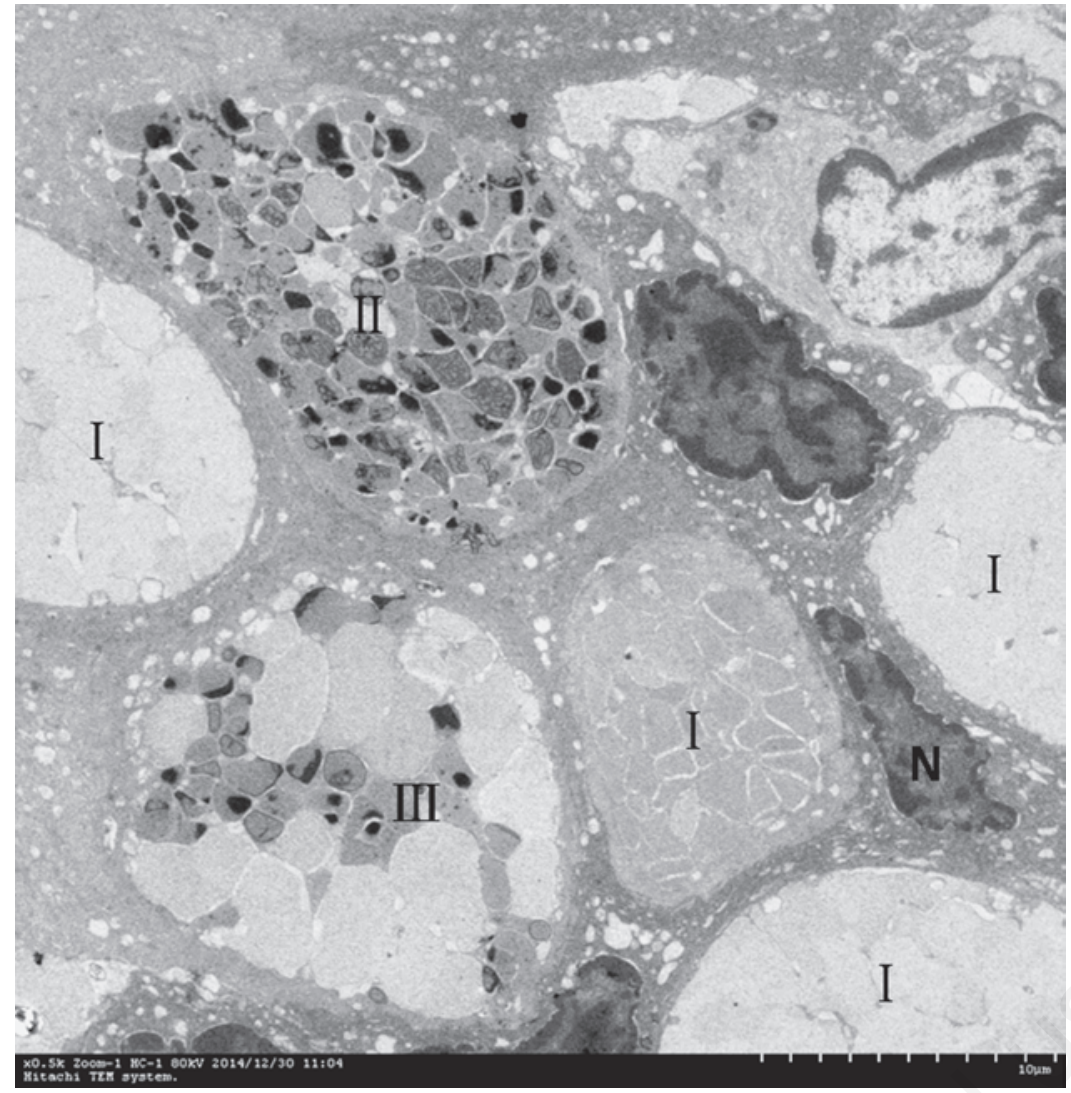

Figure 5. Higher magnification micrographs showing detail of a section of epithelium containing various mucous cells based on their heterogeneous vesicles. I, ELV-MC; II, EDV-MC; III, MV-MC.

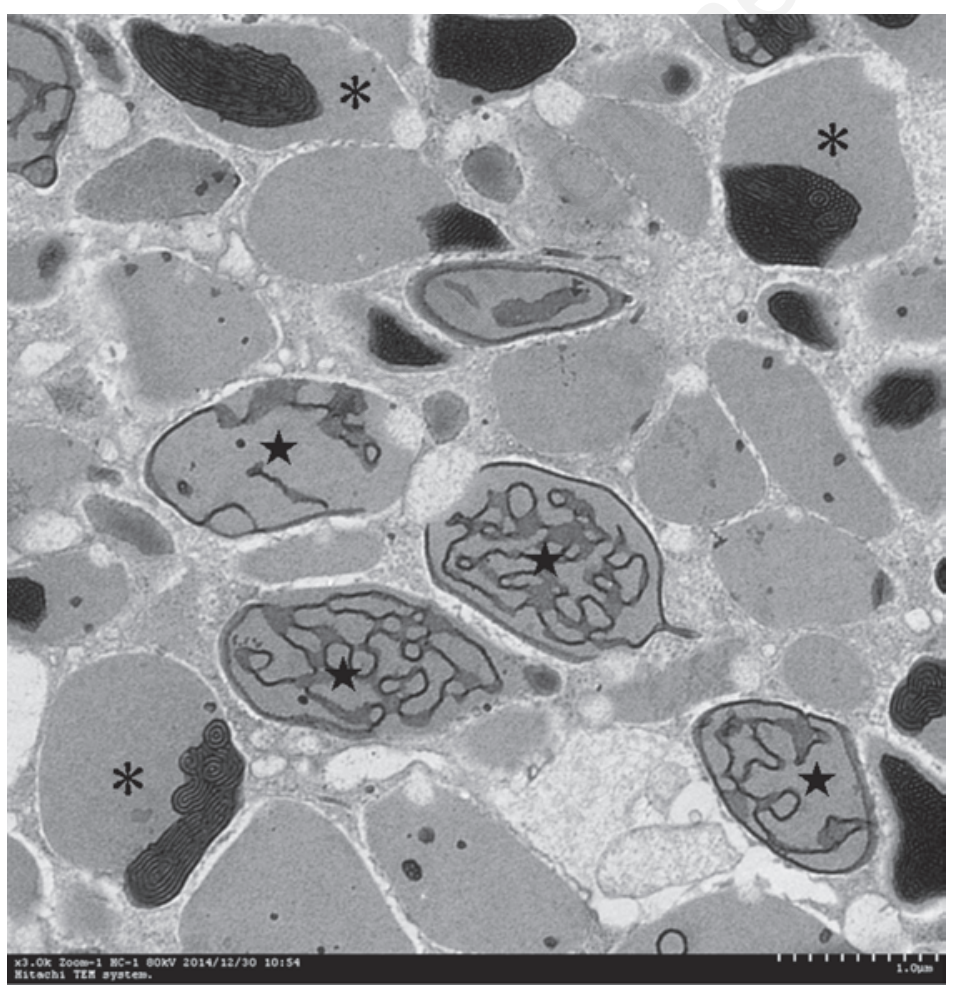

Figure 6. Higher magnification micrographs showing detail of vesicles of EDV-MC. Two kinds of high electron-dense materials were present in the vesicles of EDV-MC, namely off-centered, fingerprint-like material (asterisk) and irregular thread material (star). been demonstrated in previous literatures. We hypothesize that high electron-dense material in the vesicles could serve as a core. The various electron-dense materials of vesicles might appear in different developmental stages of maturational processes of vesicle content. Whether electron-dense and electron-lucent vesicles play different roles in the esophagus of Chinese giant salamander needs to be further studied by isolating the two cell types and analyzing molecular components of two kinds of vesicles in the future.

Despite these structural differences between various amphibians esophagus, mucous cells and ciliated columnar cells may be common to amphibian esophagus. ${ }^{14}$ Anyway, histological structure of esophagus, two kinds of cells of esophageal epithelium, particularly, might play special role during the process of feeding. In some adult amphibians, the esophageal epithelium is usually ciliated. ${ }^{9,15}$ The ciliary movements of ciliated cells in the esophagus have been hypothesized to be involved in food traction during swallowing. ${ }^{9}$ Previous study documented that giant salamander can swallow whole crab into stomach by esophagus. ${ }^{8}$ Others studies also indicated that Chinese giant salamander can capture prey by using an alternative suction feeding mechanism. ${ }^{16,17}$ It is suggested that large foods might be engulfed rapidly into mouth and swallowed into stomach via esophagus. In this study, the esophagus formed several folds. The esophageal lumen becomes patent by folds distended when swallowing large foods. The welldeveloped muscular layer of esophagus is also flexible. All of these results suggest that the esophagus of Chinese giant salamander is elastic and can swallow hard and massive foods. The massive and hard foods can be conveyed from the oral pharynx to the stomach by the Chinese giant salamander esophagus. However, these hard foods might damage esophagus. Accordingly, esophagus of this amphibian needs some special protective structure. Here, the mucous cells of esophagus can secrete mucus, which might be transported by cilia of columnar cells covering and lubricating the esophageal cavosurface. The widespread mucus reduces friction between foods and epithelium, and facilitates the amphibian to swallow massive foods. Accordingly, we assume that the mucus produced by the esophageal mucous cells has a protective function. Additionally, a study demonstrated that the function of esophageal cilia may be cleaning by transporting the thin layers of mucins and fluid that form the interface between epithelium and luminal environment. ${ }^{18}$ Cilia can discard disturbing particles or pathogens trapped in the mucous film from the esophagus by ciliary waving and propulsion to keep the esophagus clean. ${ }^{9}$ In conclusion, mucous 


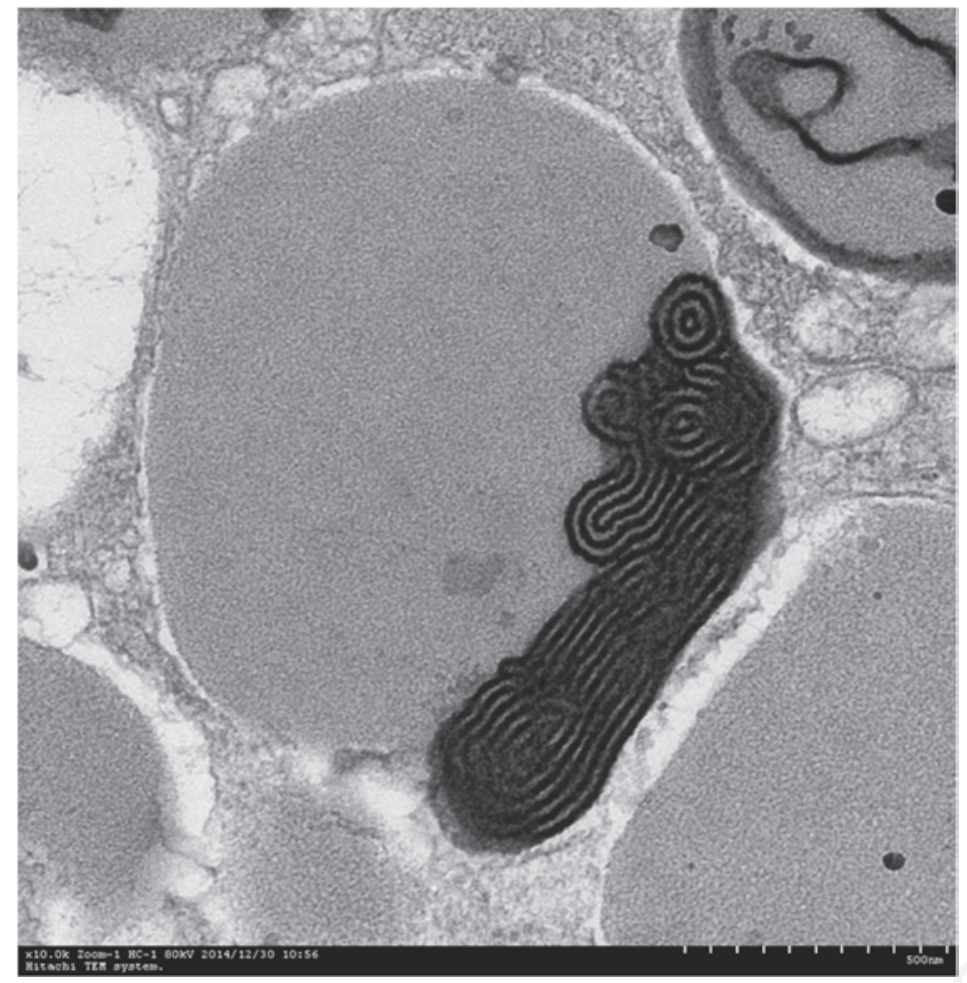

Figure 7. Higher magnification micrographs showing detail of vesicles of EDV-MC with a high electron-dense, off-centered fingerprint-like material.

cells with heterogeneous vesicles and columnar cells with cilia were present in the esophagus epithelium of Chinese giant salamander. These mucous cells and columnar cells could play important roles in food swallowing, protection, clean and infections resistance by their mucus and cilia.

\section{References}

1. Stuart SN, Chanson JS, Cox NA, Young BE, Rodrigues AS, Fischman DL, Waller RW. Status and trends of amphibian declines and extinctions worldwide. Science 2004; 306:1783-6.

2. Gomes A, Giri B, Saha A, Mishra R, Dasgupta SC, Debnath A, Gomes A. Bioactive molecules from amphibian skin: their biological activities with reference to therapeutic potentials for possible drug development. Indian J Exp Biol 2007;45: 579-93.
3. Murphy RW, Fu J, Upton DE, de Lema T, Zhao EM. Genetic variability among endangered Chinese giant salamanders, Andrias davidianus. Mol Ecol 2000;9:1539-47.

4. Xie F, Lau MW, Stuart SN, Chanson JS, Cox NA, Fischman DL. Conservation needs of amphibians in China: a review. Sci China C Life Sci 2007;50:265-76.

5. Wang L, Yang H, Li F, Zhang Y, Yang Z, Li Y, Liu X. Molecular characterization, tissue distribution and functional analysis of macrophage migration inhibitory factor protein (MIF) in Chinese giant salamanders Andrias davidianus. Dev Comp Immunol 2013;39:161-8.

6. Shubin N, Wake DB, Crawford AJ. Morphological variation in the limbs of Taricha granulosa (Caudata: Salamandridae): evolutionary and phylogenetic implications. Evolution 1995;49: 874-84.

7. Vieira-Lopes DA, Pinheiro NL, Sales A, Ventura A, Araújo FG, Gomes ID, Nascimento AA. Immunohistochemical study of the digestive tract of Oligosarcus hepsetus. World J Gastroenterol 2013;19: 1919-29.

8. Li P, Zhang Y, Ma C, Wang Z. The anatomical and histological studies of the digestive tract on Andrias davidianus. J Shaanxi Normal Univ (Natural Science Edition) 1991;19:61-64.

9. Gallego-Huidobro J, Pastor LM, Calvo A. Histology of the esophagus of the adult frog Rana perezi (Anura: Ranidae). J Morphol 1992;212:191-200.

10. Liquori GE, Mastrodonato M, Zizza S, Ferri D. Glycoconjugate histochemistry of the digestive tract of Triturus carnifex (Amphibia, Caudata). J Mol Histol 2007; 38:191-9.

11. Liquori GE, Scillitani G, Mastrodonato M, Ferri D. Histochemical investigations on the secretory cells in the oesophagogastric tract of the Eurasian green toad, Bufo viridis. Histochem J 2002;34:517-24.

12. Imai M, Shibata T, Izumi T. Histological and histochemical investigations on Japanese lizard esophagus. Okajimas Folia Anat Jpn 1992;69:25-34.

13. Uriona TJ, Farmer CG, Dazely J, Clayton F, Moore J. Structure and function of the esophagus of the American alligator (Alligator mississippiensis). J Exp Biol 2005;208:3047-53.

14. Koyama $H$. The postbranchial digestive tract of the ascidian, Polyandrocarpa misakiensis (Tunicata: Ascidiacea). 1. Oesophagus. Zoolog Sci 2011;28:118-25.

15. Setoguti T, Matsumura H, Chen HS. Correlated histochemical and electron microscopic studies of the esophageal epithelium in the salamander, Hynobius nebulosus. Arch Histol Jpn 1987;50:283-97.

16. Heiss E, Natchev N, Gumpenberger M, Weissenbacher A, Van Wassenbergh S. Biomechanics and hydrodynamics of prey capture in the Chinese giant salamander reveal a high-performance jaw-powered suction feeding mechanism. J R Soc Interface 2013;10:1-12.

17. Fortuny J, Marcé-Nogué J, Heiss E, Sanchez M, Gil L, Galobart À. 3D bite modeling and feeding mechanics of the largest living amphibian, the Chinese giant salamander Andrias davidianus (Amphibia: Urodela). PLoS One 2015;10:e0121885.

18. Spungin B, Silberberg A. Stimulation of mucus secretion, ciliary activity, and transport in frog palate epithelium. Am J Physiol 1984;247:C299-308. 